\title{
Malignant Vulvar Neoplasm
}

National Cancer Institute

\section{Source}

National Cancer Institute. Malignant Vulvar Neoplasm. NCI Thesaurus. Code C7502.

A primary or metastatic malignant neoplasm involving the vulva. 